\title{
PRODUKSI UDANG DAN POLA MUSIM PENANGKAPANNYA DI PERAIRAN KABUPATEN PANGKEP
}

\author{
Shrimp Production And Catching Seasons In Pangkep District Water \\ Oleh: \\ Ihsan ${ }^{1)}$ dan Mustamin Tajuddin ${ }^{2)}$ \\ 1), 2). Program studi pemanfaatan sumberdaya perikanan FPIK UMI \\ Korespondensi: ihsan.ihsan@umi.ac.id
}

Diterima: Tanggal 25 januari 2019; disetuji 30 April 2019

\begin{abstract}
ABTSRACT
Shrimp is a type of crustacean and is included in the marine fishery commodity which has important economic value and is currently hunted by fishermen and is commonly found in coastal waters. The purpose of this study was to determine the Shrimp Production and Seasonal Catching Pattern in the Waters of Pangkep Regency. Its usefulness is as a foundation material in the use of shrimp resources in the waters of Pangkep Regency. Data collected consists of primary data and secondary data. Primary data is obtained by direct observation in the field through a field survey method (visual recall) to portray the conditions of crab resources. While secondary data was collected from the relevant agencies according to the attributes that will be reviewed and recorded data from collecting fishermen in the coastal areas and small islands of Pangkep Regency. Shrimp production from trammel net and mini trawl catches in the waters of the Sigeri District of Pangkep Regency in 2015 consisted of 706 tons of white shrimp and dogol shrimp 4,481 tons, while in 2016706 tons of white shrimp and dogol shrimp 4,481 tons. Analysis of the percentage of shrimp fishing season index in the waters of Pangkep Regency, occurred in January, February, March and April. The highest percentage of fishing season index occurs in January each year.
\end{abstract}

Keyword: Production; Shrimp; Pattern; Catching Season; Waters.

\begin{abstract}
ABSTRAK
Udang merupakan jenis crustacea dan termasuk dalam komoditi perikanan laut yang bernilai ekonomis penting dan saat ini banyak diburu oleh nelayan dan umumnya ditemukan di perairan pantai. Tujuan penelitian ini adalah untuk mengetahui Produksi Udang dan Pola Musim Penangkapannya di Perairan Kabupaten Pangkep. Kegunaannya adalah sebagai bahan landasan dalam pemanfaatan sumberdaya udang di perairan Kabupaten Pangkep. Data dikumpulkan terdiri dari data primer dan data sekunder. Data primer diperoleh dengan cara pengamatan langsung di lapangan melalui metode survei lapang (visual recall) terhadap potretkondisi sumberdaya rajungan. Sedangkan data sekunder dikumpulkan dari instansi terkait sesuai atribut yang akan dikaji dan mencatat data-data dari nelayan pengumpul yang ada di wilayah pesisir dan pulau-pulau kecil Kabupaten Pangkep. Produksi udang dari hasil tangkapan trammel net dan mini trawl di perairan Kecamatan Sigeri Kabupaten Pangkep tahun 2015 yang terdiri dari udang putih 706 ton dan Udang dogol 4.481 ton, sedangkan tahun 2016 udang putih 706 ton dan udang dogol4.481 ton. Analisis persentase indeks musim penangkapan udang di perairan Kabupaten Pangkep, terjadi pada bulan Januari, Februari, Maret dan April. Persentase indeks musim penangkapan tertinggi terjadi pada bulan Januari setiap tahun.
\end{abstract}

Keyword: Produksi; Udang; Pola; Musim Penangkapan;Perairan. 



\section{PENDAHULUAN}

Udang merupakan jenis

crustacea dan termasuk dalam

komoditi perikanan laut yang bernilai ekonomis penting dan saat ini banyak diburu oleh nelayan dan umumnya ditemukan di perairan pantai. Komoditas udang putih banyak di ekspor ke luar negeri dalam bentuk olahan beku. Untuk memenuhi kebutuhan pasokan masyarakat, sampai sekarang masih mengandalkan dari penangkapan di laut disamping budidaya di tambak-tambak yang dilakukan oleh petani tambak dengan berbagai jenis skala usaha.

Setiap tahun permintaan udang mengalami peningkatan dan akan memberikan dampak negatif pada keberadaan populasi udang putih di laut, baik secara langsung maupun secara tidak langsung, sehingga dikhawatirkan menyebabkan terjadi kelebihan tangkap udang putih.

Udang hidup di perairan dangkal mulai kedalaman 2 - $70 \mathrm{~m}$ dengan substrat berpasir sampai berpasir berlumpur. Udang banyak berada di area perairan sekitar mangrove dan padang lamun. Pada fase zoea-crab banyak ditemukan di daerah intertidal, termasuk udang dewasa pada umur 1 tahun. Sumberdaya udang putih banyak ditangkap oleh nelayan dengan menggunakan gillnet dasar, mini trawl, pukat pantai, dan jaring lingkar. Udang ditangkap dalam jumlah yang sangat banyak untuk dijual dalam bentuk segar dan beku di pasaran lokal. Tingkah laku udang dipengaruhi oleh beberapa faktor alami diantaranya adalah perkembangan hidup, kebiasaan makan, pengaruh siklus bulan, reproduksi dan pengaruh paramater oseanografi diantaranya pasang surut. Udang termasuk hewan pasif, karena mengubur diri dalam sedimen lumpur. Udang di dalam budidaya di pertambakam, pada saat terjadi pasang surut aktif berenang mengelilingi caren. Untuk menangkap udang digunakan berbagai jenis alat tangkap diantaranya gillnet dasar, dan mini trawl. Alat tangkap gillnet di operasikan secara pasif di dasar perairan dan mini trawl di operasikan secara aktif oleh nelayan dengan di tarik (dihela) dengan kapal pada kecepatan tertentu di dasar perairan.

Pola musim udang, mengintegrasikan berbagai informasi yang penting dalam eksploitasi sumberdaya, dengan demikian musim penangkapan dapat diprediksi lebih 
tepat. Hasil penelitian ini diharapkan meningkatkan efisiensi dan efektifitas dalam eksploitasi sumberdaya rajungan. Kecermatan dalam melakukan eksplorasi daerah penangkapan akan menghasilkan akurasi yang tinggi dan pemanfaatan sumberdaya udangyang tepat akan meningkatkan keuntungan keberlanjutan usaha perikanan tangkap udang.

Untuk mencapai hal tersebut maka dukungan informasi yang terdiri dari pola musim penangkapan udang sangat diperlukan. Sehubungan dengan hal tersebut maka perlu penelitian tentang pola musim penangkapan rajungan secara partisipatif terhadap penangkapan udang di perairan Kabupaten Pangkep.

Adapun tujuan penelitian ini adalah untuk mengetahui Produksi Udang dan Pola Musim Penangkapannya di Perairan Kabupaten Pangkep. Sedangkan kegunaannya adalah sebagai bahan landasan dalam pemanfaatan sumberdaya udang di perairan Kabupaten Pangkep.

\section{METODE PENELITIAN}

Penelitian ini dilaksanaan pada bulan Maret sampai Bulan September
2016, di wilayah pesisir pantai dan pulau-pulau Kabupaten Pangkep.

\section{Kebutuhan Data dan Metode Penelitian}

Untuk memenuhi kebutuhan data, dilakukan pengumpulan data primer dan data sekunder. Data primer diperoleh dengan cara pengamatan langsung di lapangan melalui metode survei lapang (visual recall) terhadap potretkondisi sumberdaya rajungan, serta melakukan wawancara langsung dengan nelayan (responden) di wilayah pesisir dan pulau-pulau untuk mengumpulkan data sosial, ekonomi dan budaya melalui metode focus group discussion (FGD). Sedangkan pengambilan data sekunder dilakukan dengan cara mengumpulkan data dari instansi terkait sesuai atribut yang akan dikaji dan mencatat data-data dari nelayan pengumpul yang ada di wilayah pesisir dan pulau-pulau kecil Kabupaten Pangkep.

Data primer yang dikumpulkan meliputi: (a) biofisik: melakukan survey

penangkapanrajunganterhadapalattang kap yang digunakannelayan, mencatat produksi rajungan, (kg) yang dikumpulkan adalah produksi hasil tangkapan nelayan dari ketiga jenis alat 
tangkap yang beroperasi di perairan Kabupaten Pangkep selama 5 tahun di seluruh nelayan kolektor di kecamatan pesisir dan pulaupulaukecilKabupatenPangkep yang ditetapkansebagailokasipeneltian.

Mencatat kordinat lokasi penangkapan nelayan untuk ketiga alat tangkap yang dioperasikan nelayan pada saat ikut serta beroperasi ke lapangan, melakukan wawancara dengan nelayan yang mewakili nelayan gillnet rajungan, bubu lipat, dan mini trawl,mempelajari tata cara pengoperasian alat tangkap dan;(b) alat tangkap: melakukan identifikasi dan inventarisasi jenis alat tangkap yang dioperasikan, mendeskripsikan jenisjenis alat tangkap yang digunakan nelayan untuk menangkap rajungan dan mencatat lokasi penangkapan dan hasil tangkapan setiap melakukan operasi dalam kurung waktu tertentu selama penelitian.

Data sekunder dikumpulkan melalui penelusuran berbagai pustaka yang ada, dan berbagai laporan yang diperoleh dari berbagai instansi dan institusi terkait sesuai atribut yang akan dikaji. Pengumpulan data sekunder dilakukan melalui studi kepustakaan seperti laporan-laporan hasil survei, jurnal ilmiah dan publikasi-publikasi lainnya serta peta-peta yang tersedia.

Pemilihan responden dilakukan dengan cara purposive samplingyaitu pemilihan secara sengaja dengan pertimbangan responden adalah pelaku atau memahami dengan baik persoalan yang terdiri dari pemerintah, swasta, masyarakat dan nelayan yang dapat memberikan informasi secara akurat, pengambil kebijakan dan sebagai pelaku.

\section{Analisis Data}

Analisis data yang dilakukan adalah menganalisis pola musim penangkapan rajungan. Dalam pola musim penangkapan ditentukan dengan menggunakan teknik analisis deret waktu (time series) terhadap hasil tangkapan persatuan upaya penangkapan bulanan rajungan selama enam tahun terakhir. Penentuannya menggunakan metode rata-rata bergerak (moving average), sebagaimana diutarakan oleh Wiyono (2001) dalamSyahrir (2011) sebagai berikut: 1) menyusun data deret waktu CPUE bulan pertama tahun ke (n) hingga bulan ke (n) tahun (n), ; b) Menyusun rata-rata bergerak CPUE (n) bulan (RG) ; c) menyusun rata-rata bergerak CPUE terpusat (RGP); d) 

menghitung rasio rata-rata untuk tiap bulan $(\mathrm{Rb})$ dan e) menyusun nilai ratarata dalam satu matrik berukuran $\mathrm{j}$ x $\mathrm{i}$ yang disusun untuk setiap bulan dimulai kuartal (bulan) III kemudian menghitung rata-rata atau variasi musim dan selanjutnya menghitung indeks musim penangkapan antara lain: 1) rasio ratarata untuk bulan ke-i (RRB); 2) jumlah rasio rata-rata bulanan (JRRB) dan 3) indeks musim penangkapan.

Penentuan musim ikan dengan Kriteria-kriteriaialah jika indeks musim lebih dari 1 (lebih dari $100 \%$ ) atau di atas rata-rata, dan bukan musim jika indeks musim kurang dari 1 (kurang dari $100 \%)$. Apabila IM = $1(100 \%)$, nilai ini sama dengan harga rata-rata bulanan sehingga dapat dikatakan dalam keadaan normal atau berimbang.

HASIL DAN PEMBAHASAN

Produksi Udang

Produksi udang dari hasil tangkapan trammel net dan mini trawl diperairan Kecamatan Sigeri Kabupaten Pangkep pada tahun 2013, tercatat pada nelayan kolektor hanya pada November dan Desember tahun 2013. Hasil identifikasi udang yang tertangkap dengan menggunakan alat tangkap trammel net dan mini trawl terdiri dari udang putih dan Udang dogol, selengkapnya disajikan pada tabel berikut ini:

Tabel 1. Produksi udang dari hasil tangkapan trammel net dan mini trawl di perairan Kecamatan Sigeri Kabupaten Pangkep tahun 2013

\begin{tabular}{|c|r|r|r|}
\hline \multirow{2}{*}{ Bulan } & \multicolumn{2}{|c|}{ Produksi } & \multirow{2}{*}{ Total (kg) } \\
\cline { 2 - 3 } & Udang putih & Udang dogol & 159,7 \\
\hline November & 23,6 & 136,1 & 384,1 \\
\hline Desember & 97,9 & 286,2 & 543,8 \\
\hline Jumlah & 121,5 & 422,3 & \\
\hline
\end{tabular}

Sumber: diolah berdasarkan hasil pencatatan pada nelayan kolektor tahun 2016
Sedangkan produksi udang dari hasil
udang putih sebanyak 930,8 ton dan tangkapan trammel net dan mini trawl Udang dogol sebanyak 6119,6 ton. Total diperairan Kecamatan Sigeri Kabupaten produksi udang sebanyak 7050,4 ton, Pangkep tahun 2014 yang terdiri dari selengkapnya disajikan pada tabel berikut: 
Tabel 2. Produksi udang dari hasil tangkapan trammel net dan mini trawl diperairan Kecamatan Sigeri Kabupaten Pangkep tahun 2014

\begin{tabular}{|l|r|r|r|}
\hline \multirow{2}{*}{ Bulan } & \multicolumn{2}{|c|}{ Produksi } & \multirow{2}{*}{ Total (kg) } \\
\cline { 2 - 3 } & Udang putih & Udang dogol & 1449,8 \\
\hline Januari & 344,2 & 1105,6 & 1437,9 \\
\hline Februari & 238,6 & 1199,3 & 861,4 \\
\hline Maret & 59,6 & 801,8 & 435,2 \\
\hline April & 29,6 & 405,6 & 676,9 \\
\hline Mei & 40,8 & 636,1 & 746,4 \\
\hline Juni & 43 & 703,4 & 271,9 \\
\hline Juli & 14,7 & 257,2 & 48,4 \\
\hline Agustus & 8,5 & 39,9 & 268,8 \\
\hline September & 16,5 & 252,3 & 211,9 \\
\hline Oktober & 4,6 & 207,3 & 190,9 \\
\hline November & 5,9 & 185 & 450,9 \\
\hline Desember & 124,8 & 326,1 & 7050,4 \\
\hline \multicolumn{1}{|c|}{ Jumlah } & 930,8 & 6119,6 & \\
\hline
\end{tabular}

Sumber: diolah berdasarkan hasil pencatatan pada nelayan kolektor tahun 2016

Sedangkan produksi udang dari hasil udang putih sebanyak 706 ton dan Udang

tangkapan trammel net dan mini trawl dogol sebanyak 4.481 ton. Total produksi diperairan Kecamatan Sigeri Kabupaten udang sebanyak 5.190 ton, selengkapnya Pangkep tahun 2015 yang terdiri dari disajikan pada tabel berikut:

Tabel 3. Produksi udang dari hasil tangkapan trammel net dan mini trawl diperairan Kecamatan Sigeri Kabupaten Pangkep tahun 2015

\begin{tabular}{|l|r|r|r|}
\hline \multirow{2}{*}{ Bulan } & \multicolumn{2}{|c|}{ Produksi } & \multirow{2}{*}{ Total (kg) } \\
\cline { 2 - 3 } & Udang putih & Udang dogol & 1.556 \\
\hline Januari & 211 & 1.345 & 1.049 \\
\hline Februari & 153 & 896 & 535 \\
\hline Maret & 73 & 462 & 500 \\
\hline April & 58 & 442 & 433 \\
\hline Mei & 58 & 375 & 154 \\
\hline Juni & 23 & 131 & 188 \\
\hline Juli & 29 & 160 & 220 \\
\hline Agustus & 21 & 199 & 336 \\
\hline September & 31 & 306 & 186 \\
\hline Oktober & 20 & 166 & - \\
\hline November & - & - & 32 \\
\hline Desember & 30 & 2 & 5.190 \\
\hline Jumlah & 706 & 4.481 & 2 \\
\hline
\end{tabular}

Sumber: diolah berdasarkan hasil pencatatan pada nelayan kolektor tahun 2016

Sedangkan produksi udang dari terdiri dari udang putih sebanyak 706 ton hasil tangkapan trammel net dan mini dan Udang dogol sebanyak 4.481 ton. trawl diperairan Kecamatan Sigeri Selama 4 bulan tercatat, produksi udang Kabupaten Pangkep tahun 2016 yang 
putih lebih banyak daripada udang dogol, selengkapnya disajikan pada tabel berikut:

Tabel 4. Produksi udang dari hasil tangkapan trammel net dan mini trawl diperairan Kecamatan Sigeri Kabupaten Pangkep tahun 2016

\begin{tabular}{|l|r|r|r|}
\hline \multirow{2}{*}{ Bulan } & \multicolumn{2}{|c|}{ Produksi } & \multirow{2}{*}{ Total (kg) } \\
\cline { 2 - 3 } & Udang putih & \multicolumn{1}{c|}{ Udang dogol } & 328,3 \\
\hline Januari & 244,6 & 83,7 & 677,1 \\
\hline Februari & 593,1 & 84 & 501 \\
\hline Maret & 484,4 & 16,6 & 142,4 \\
\hline April & 122,3 & 20,1 & 41 \\
\hline Mei & 15 & 26 & \\
\hline
\end{tabular}

Sumber: diolah berdasarkan hasil pencatatan pada nelayan kolektor tahun 2016

\section{Pola musim penangkapan udang}

Hasil analisis yang dilakukan

menunjukan bahwa Produksi dan effort

dan rata-rata bergerak CPUE terpusat udang di Kabupaten Pangkep, puncaknya pada awal tahun yakni pada bulan Januari, selanjutnya mengalami penurunan pada bulan Agustus. Selengkapnya disajikan pada tabel berikut ini:

Tabel 5. Produksi dan effort dan rata-rata bergerak CPUE terpusat udang di Kabupaten Pangkep

\begin{tabular}{|l|l|r|r|r|r|r|r|}
\hline Tahun & Bulan & Produksi & effort & \multicolumn{1}{c|}{ CPUE } & \multicolumn{1}{c|}{ RGi } & RGPi & \multicolumn{1}{c|}{ Rbi } \\
\hline \multirow{8}{*}{2014} & Januari & 1449,8 & 32 & 45,31 & & & \\
\cline { 2 - 8 } & Februari & 1437,9 & 32 & 44,93 & 21,33 & 10,67 & 4,21 \\
\cline { 2 - 8 } & Maret & 861,4 & 32 & 26,92 & 16,14 & 18,74 & 1,44 \\
\cline { 2 - 8 } & April & 435,2 & 32 & 13,60 & 16,69 & 16,41 & 0,83 \\
\cline { 2 - 8 } & Mei & 676,9 & 32 & 21,15 & 17,19 & 16,94 & 1,25 \\
\cline { 2 - 8 } & Juni & 746,4 & 32 & 23,33 & 18,36 & 17,77 & 1,31 \\
\cline { 2 - 8 } & Juli & 271,9 & 32 & 8,50 & 18,64 & 18,50 & 0,46 \\
\cline { 2 - 8 } & Agustus & 48,4 & 32 & 1,51 & 17,62 & 18,13 & 0,08 \\
\cline { 2 - 8 } & September & 268,8 & 32 & 8,40 & 16,77 & 17,20 & 0,49 \\
\cline { 2 - 8 } & Oktober & 211,9 & 32 & 6,62 & 16,94 & 16,86 & 0,39 \\
\cline { 2 - 8 } & Nopember & 190,9 & 32 & 5,97 & 16,31 & 16,63 & 0,36 \\
\cline { 2 - 8 } & Desember & 450,9 & 32 & 14,09 & 14,77 & 15,54 & 0,91 \\
\hline 2012 & Januari & 1.556 & 32 & 48,63 & 14,55 & 14,66 & 3,32 \\
\cline { 2 - 8 } & Februari & 1.049 & 32 & 32,78 & 14,99 & 14,77 & 2,22 \\
\cline { 2 - 8 } & Maret & 535 & 32 & 16,72 & 15,17 & 15,08 & 1,11 \\
\cline { 2 - 8 } & April & 500 & 32 & 15,63 & 15,10 & 15,13 & 1,03 \\
\cline { 2 - 8 } & Mei & 433 & 32 & 13,53 & 15,00 & 15,05 & 0,90 \\
\cline { 2 - 8 } & Juni & 154 & 32 & 4,81 & 19,00 & 17,00 & 0,28 \\
\cline { 2 - 8 } & Juli & 188 & 32 & 5,88 & 14,95 & 16,97 & 0,35 \\
\cline { 2 - 8 } & Agustus & 220 & 32 & 6,88 & 12,21 & 13,58 & 0,51 \\
\cline { 2 - 8 } & September & 336 & 32 & 10,50 & 10,82 & 11,52 & 0,91 \\
\cline { 2 - 8 } & Oktober & 186 & 32 & 5,81 & 9,52 & 10,17 & 0,57 \\
\cline { 2 - 8 } & Nopember & 154 & 32 & 4,81 & 8,39 & 8,95 & 0,54 \\
\cline { 2 - 8 } & Desember & 32 & 32 & 62,00 & 7,99 & 8,19 & 7,57 \\
\hline
\end{tabular}

Sumber: diolah berdasarkan wawancara dan pengamatan selama penelitian, 2016 

Rasio rata-rata untuk setiap penangkapan tertinggi pada bulan bulan udang di perairan Kabupaten Januari sebesar 345 dan terendah pada Pangkep, tertinggi pada bulan januari bulan Agustus sebesar 9. Selengkapnya yakni 3,32 dan terendah pada bulan disajikan pada tabel berikut ini:

Juni sebesar 0,28. Indeks musim

Tabel 6. Rasio rata-rata dan indeks musim penangkapan untuk setiap bulan udang di perairan Kabupaten Pangkep

\begin{tabular}{|l|c|c|c|}
\hline \multicolumn{1}{|c|}{ Bulan } & Juli 2014 - Juni 2015 & RRBi & IMP \\
\hline Juli & 0,459323 & 0,46 & 48 \\
\hline Agustus & 0,083423 & 0,08 & 9 \\
\hline September & 0,488394 & 0,49 & 51 \\
\hline Oktober & 0,392789 & 0,39 & 41 \\
\hline Nopember & 0,358826 & 0,36 & 37 \\
\hline Desember & 0,906939 & 0,91 & 94 \\
\hline Januari & 3,317786 & 3,32 & 345 \\
\hline Februari & 2,219440 & 2,22 & 231 \\
\hline Maret & 1,108598 & 1,11 & 115 \\
\hline April & 1,032391 & 1,03 & 107 \\
\hline Mei & 0,898908 & 0,90 & 93 \\
\cline { 1 - 2 } Juni & 0,283069 & 0,28 & 29 \\
\cline { 1 - 2 } Jumlah & 11,5 & & \\
\cline { 1 - 2 } FK & 103,9 & & \\
\cline { 1 - 2 } & &
\end{tabular}

Sumber: diolah berdasarkan wawancara dan pengamatan selama penelitian, 2016

Selanjutnya hasil analisis musim penangkapan tertinggi terjadi persentase indeks musim penangkapan pada bulan Januari setiap tahun. Uraian udang di perairan Kabupaten Pangkep, selengkapnya disajikan pada tabel dan terjadi pada bulan Januari, Februari, gambar berikut ini:

Maret dan April. Persenetase indeks

Tabel 7. Persentase indeks musim penangkapan udang di perairan Kabupaten Pangkep

\begin{tabular}{|c|l|r|}
\hline No & \multicolumn{1}{|c|}{ Musim } & IMP (\%) \\
\hline 1 & Januari & 344,7 \\
\hline 2 & Februari & 230,6 \\
\hline 3 & Maret & 115,2 \\
\hline 4 & April & 107,3 \\
\hline 5 & Mei & 93,4 \\
\hline 6 & Juni & 29,4 \\
\hline 7 & Juli & 47,7 \\
\hline 8 & Agustus & 8,7 \\
\hline 9 & September & 50,7 \\
\hline 10 & Oktober & 40,8 \\
\hline
\end{tabular}




\begin{tabular}{|l|l|r|}
11 & Nopember & 37,3 \\
\hline 12 & Desember & 94,2 \\
\hline
\end{tabular}

Sumber: diolah berdasarkan wawancara dan pengamatan selama penelitian, 2016

Selanjutnya pada gambar dibawah ini tahunnya. Selanjutnya pada bulan Mei menunjukan bahwa pola musim sampai Desember adalah musim penangkapan udang di perairan Paceklik. Uraian selengkapnya Kabupaten Pangkep mencapai disajikan pada gambar berikut ini: puncaknya pada bulan Januari,

Februari, Maret dan April setiap

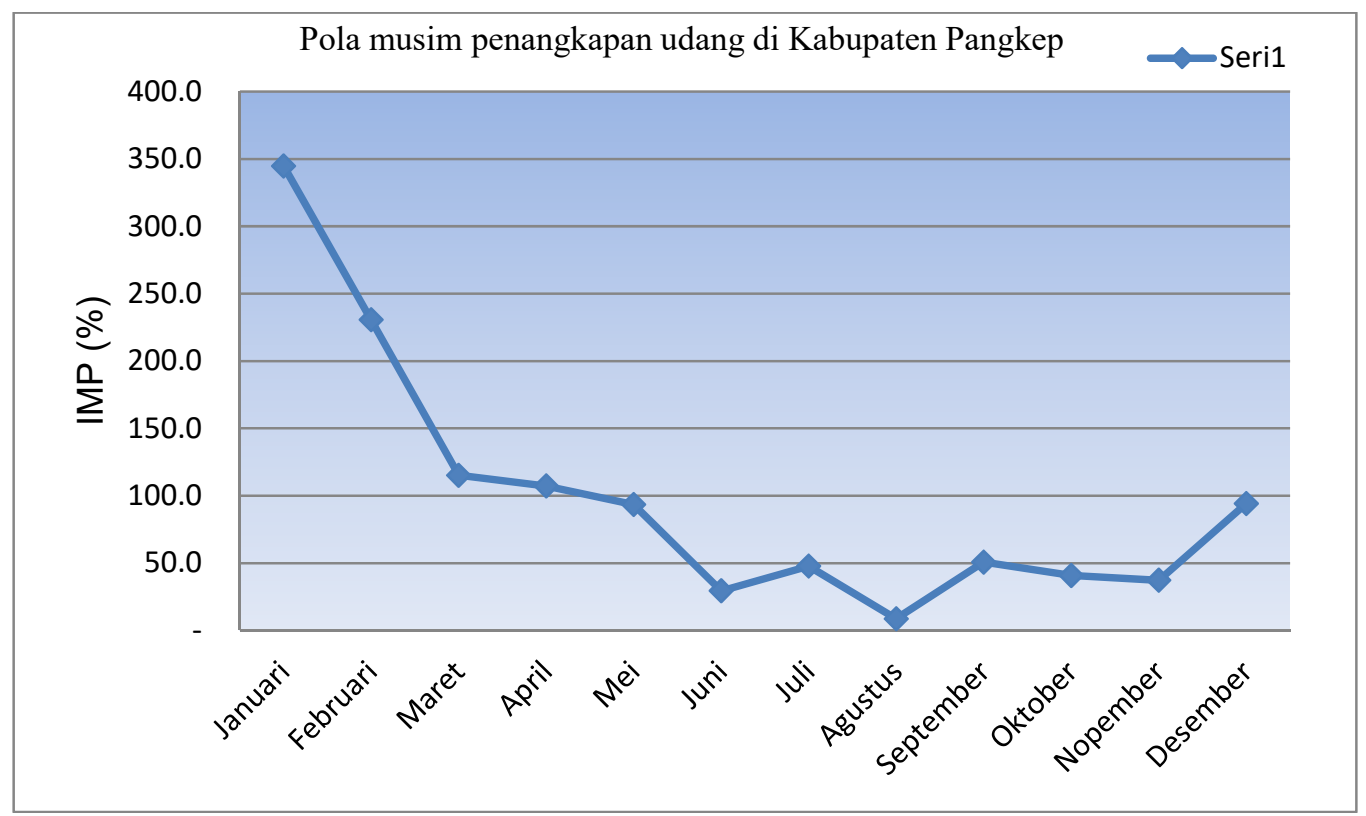

Gambar 1. Grafik Persentase indeks musim penangkapan udang di perairan Kabupaten Pangkep 


\section{KESIMPULAN}

1. Produksi udang dari hasil tangkapan trammel net dan mini trawl di perairan Kecamatan Sigeri Kabupaten Pangkep tahun 2015 yang terdiri dari udang putih sebanyak 706 ton dan Udang dogol sebanyak 4.481 ton, sedangkan tahun 2016 udang putih sebanyak 706 ton dan udang dogol sebanyak 4.481 ton.

2. Analisis persentase indeks musim penangkapan udang di perairan Kabupaten Pangkep, terjadi pada bulan Januari, Februari, Maret dan April. Persentase indeks musim penangkapan tertinggi terjadi pada bulan Januari setiap tahun.

\section{SARAN}

\begin{tabular}{llr}
\multicolumn{2}{c}{ Berdasarkan } & kesimpulan, \\
disarankan & perlunya & dilakukan \\
penelitian lebih lanjut & tentang \\
dinamika pupulasi udang yang & yangan \\
tertangkap sehingga dapat ditetapkan \\
musim pemijahan udang di perairan \\
Kabupaten Pangkep.
\end{tabular}

\section{UCAPAN TERIMA KASIH}

Tulisan ini merupakan bagian dari penelitian dasar unggulan perguruan tinggi dan penulis mengucapkan terima kasih kepada Rektor Universitas MuslimIndonesia melalui lembaga penelitian dan pengembangan sumberdaya manusia (LP2S) UMI yang telah membiayai penelitian ini.

\section{DAFTAR PUSTAKA}

Ayodhyoa, A. U., 1981. MetodePenangkapanIkan. PenerbitYayasanDewi Sri Bogor.

Bakhtiar, N.M, Solichin, A. Saputra, S.W. 2013. Pertumbuhan dan Laju Mortalitas Udang karang Batu Hijau (Panulirus homarus) di Perairan Cilacap Jawa Tengah Diponegoro Journal Of Maquares Management of Aquatic Resources Volume 1, Nomor 4, Tahun 2013, Halaman 110.

Dahuri R. 1993. Model Pembangunan Sumberdaya Perikanan secara Berkelanjutan.Prosiding Simposium Perikanan Indonesia I. Hal 297-316

Dinas Kelautan dan Perikanan(DKP) Propinsi Sulawesi Selatan. Laporan Statistik Perikanan. Tahun 2006 - 2013.

Fauzi, M., Prasetyo A P, Hargiyatno, IT, Satria F., dan Utama, AA, (2013). Hubungan PanjangBerat Dan Faktor Kondisi Udang karang Batu (Panulirus Penicillatus) Di Perairan Selatan Gunung Kidul Dan Pacitan.Jurnal Ilmiah BAWAL Vol. 5 (2) Agustus 2013 : 97-102

Firnawati,

1979.StudiPerbandinganJumla hdanKomposisiJenisHasilTan gkapan Gillnet Permukaan, PertengahandanDasar di PerairanKandari.SripsiJurusan 
PemanfaatanSumberdayaPerik anan. FakultasPerikanan UMI. Ujung Pandang.

Grzimeck, B. 1970. Animal Life Encylopedia. Volume I. Vandertrand Reinhold Company. New York. 770 P. Gulland, 1987. "Fish Stok Asses Ment" FAO Fish Wolley Series Volume I Rome.

Hasrun, 1996. Kajian Beberapa Parameter Dinamika Populasi Udang Karang (Panulirus homarusL) Berdasarkan Hasil Tangkapan Jaring Insang Dasar Di Perairan Pantai Pangandaran Jawa Barat. Tesis. Program Pasca Sarjana. Institut Pertanian Bogor. Jawa Barat.

Ihsan, 2015. pemanfaatan sumberdaya rajungan (portunus pelagicus) secara berkelanjutan di perairan kabupaten pangkep provinsi sulawesi selatan. Disertasi. Sekolah

Pascasarjan. Institut Pertanian Bogor. Bogor

Kanna, Iskandar. 2006. Udang karang

(Penangkapan, Pembenihan, Pembesaran). Kanisius. Yogyakarta.

Laevesta.T and I.Hela, 1970.Fisheries Oceanography.Fishing News.London. 238 p.

Mahasin, M.Z. 2002. Kajian Stok dan Bioekonomi Udang karang (Panulirus spp) Bagi Pemanfaatan Berkelanjutan di Propinsi Daerah Istimewa
Yokyakarta. Tesis. Universitas Diponegoro Semarang.

Manoppo,

1999.SelektifitasJaringHanyu tterhadapIkanCakalang

(Katsuwonuspelamus) Di PerairanLepasPantai Selatan Jawa Barat.Tesis Program Publisher.Ptc. Ltd. Singapore.

SubanidanBarus; 1989.AlatPenangkapanIkanda $n$ Wang Laut di Indonesia.JurnalPenelitianPer ikananLaut. Nomor 50 Tabun 1989

EdisiKhusus.BadanPenelitiand anPengembanganPertanian.De partemenPertanian Jakarta. Jakarta.

SudirmandanMallawa, A; 1999.MetodePenangkapanIka $n$. BahanPengajaran. Program StudiPemanfaatanSumberday aPerikanan. JurusanPerikanan, FakultasIlmuKelautandanPeri kanan UNHAS. Ujung Pandang.

Sulthan, $\mathrm{M}$; 1985.PengaruhIntensitasCah ayaTerhadapVasilTangkapan Pada JaringInsang . Tesis.JurusanPerikananFakult asPeternakan UNHAS.

Von Brandt, A; 1984.Fishing Catching Methods of The World Third Edition. Fishing News Book.Farnham.418 p. 